\title{
Online optimization of fluid catalytic cracking process via a hybrid model based on simplified structure-oriented lumping and case-based reasoning
}

Ge He ${ }^{1,2}$, Chenglin Zhou ${ }^{3}$, Tao Luo ${ }^{1 *}$, Li Zhou $^{1}$, Yiyang Dai ${ }^{1}$, Yagu Dang ${ }^{1}, \mathrm{Xu} \mathrm{Ji}^{1 *}$

1. School of Chemical Engineering, Sichuan University, Chengdu 610065, China

2. Lanzhou Petrochemical of PetroChina Company Limited, Lanzhou 730060, China

3. Hangzhou XINFU Energy Technology Company Limited, Hangzhou 310000, China

*Corresponding authors: Dr.-Ing Tao Luo (tao.luo@scu.edu.cn) and Prof. Dr. Xu Ji
(jxhhpb@163.com) at School of Chemical Engineering, Sichuan University, Chengdu 610065, P.
R. China.

Contents of the Supporting Information:

1. Characterization of the FCC feed oil

2. Key molecular structures of the FCC feed oil

3. Data pre-processing

4. The steady-state analysis

5. The input variables for modeling

6. Feature importance of the input variables 


\section{Characterization of the FCC feed oil}

Table S1. Hydrocarbon composition

\begin{tabular}{|c|c|c|}
\hline Hydrocarbon & $\begin{array}{c}\text { Content in waxy oil } \\
\text { (wt.\%) }\end{array}$ & $\begin{array}{c}\text { Content in residual oil } \\
\text { (wt.\%) }\end{array}$ \\
\hline Alkane & 36.6 & 18.5 \\
\hline Cycloalkane & 9.6 & 9.6 \\
\hline Bicyclic alkane & 12.1 & 10.4 \\
\hline Tricyclic alkane & 8.1 & 9.2 \\
\hline Tetracyclic alkane & 4.7 & 3 \\
\hline Pentacycloalkanes & 1.7 & 1.1 \\
\hline Hexacycloalkane & 0.3 & 0 \\
\hline Total naphthene & 36.5 & 33.3 \\
\hline Alkyl benzene & 4.5 & 7.4 \\
\hline Naphthenic benzene & 4.1 & 5.8 \\
\hline Bicyclic alkylbenzene & 3.8 & 5 \\
\hline Total monocyclic aromatics & 12.4 & 18.2 \\
\hline Naphthalenes & 2.6 & 3.8 \\
\hline Acenaphthene + Dibenzofuran & 2.4 & 3.4 \\
\hline Fluorene & 2.7 & 4.5 \\
\hline Total bicyclic aromatics & 7.7 & 11.7 \\
\hline Phenanthrenes & 2.1 & 3.3 \\
\hline Naphthenic phenanthrene & 0.9 & 1.1 \\
\hline Total tricyclic aromatics & 3 & 4.4 \\
\hline Pyrenes & 1 & 0.7 \\
\hline Flexion & 0.6 & 0.6 \\
\hline Total tetracyclic aromatics & 1.6 & 1.3 \\
\hline Perylenes & 0.3 & 0.6 \\
\hline Dibenzanthracene & 0 & 0.2 \\
\hline Total pentacyclic aromatics & 0.3 & 0.8 \\
\hline Benzothiophene & 0.6 & 0.9 \\
\hline Dibenzothiophene & 0.2 & 0.2 \\
\hline Naphthobenzothiophene & 0.1 & 0 \\
\hline Total thiophene & 0.9 & 1.1 \\
\hline Aromatic hydrocarbons (no identified) & 1 & 5 \\
\hline Total aromatics & 26.9 & 42.5 \\
\hline Colloid & 0 & 5.7 \\
\hline Total & 100 & 100 \\
\hline
\end{tabular}


Table S2. Carbon number distribution of saturated hydrocarbon in waxy oil

\begin{tabular}{|c|c|c|c|c|c|c|c|c|c|}
\hline $\mathrm{Z}$ & +2 & +2 & +2 & 0 & -2 & -4 & -6 & -8 & -10 \\
\hline $\mathrm{C} \#$ & Alkane & N-alkane & Isoalkane & Cycloalkane & $\begin{array}{c}\text { Bicyclic } \\
\text { alkane }\end{array}$ & $\begin{array}{c}\text { Tricyclic } \\
\text { alkane }\end{array}$ & $\begin{array}{c}\text { Tetracyclic } \\
\text { alkane }\end{array}$ & $\begin{array}{c}\text { Pentacycl } \\
\text { oalkanes }\end{array}$ & Hexacycloalkane \\
\hline 11 & 0.03 & & 0.03 & 0.06 & & 0.01 & & & \\
\hline 12 & 0.10 & 0.03 & 0.07 & 0.07 & 0.04 & 0.01 & & & \\
\hline 13 & 0.20 & 0.05 & 0.14 & 0.10 & 0.06 & 0.03 & 0.01 & & \\
\hline 14 & 0.50 & 0.11 & 0.39 & 0.16 & 0.13 & 0.06 & 0.02 & & 0.00 \\
\hline 15 & 0.73 & 0.18 & 0.56 & 0.23 & 0.24 & 0.12 & 0.02 & 0.01 & 0.00 \\
\hline 16 & 1.05 & 0.24 & 0.81 & 0.31 & 0.45 & 0.25 & 0.03 & 0.01 & 0.00 \\
\hline 17 & 1.54 & 0.37 & 1.17 & 0.41 & 0.48 & 0.23 & 0.04 & 0.01 & 0.00 \\
\hline 18 & 2.23 & 0.56 & 1.67 & 0.52 & 0.50 & 0.36 & 0.10 & 0.05 & 0.00 \\
\hline 19 & 3.30 & 0.91 & 2.39 & 0.64 & 0.50 & 0.58 & 0.16 & 0.03 & 0.02 \\
\hline 20 & 4.33 & 1.16 & 3.17 & 0.82 & 0.73 & 0.57 & 0.16 & 0.05 & 0.01 \\
\hline 21 & 4.36 & 1.35 & 3.01 & 0.85 & 1.02 & 0.63 & 0.32 & 0.09 & 0.02 \\
\hline 22 & 3.68 & 1.33 & 2.35 & 0.86 & 1.09 & 0.56 & 0.25 & 0.06 & 0.03 \\
\hline 23 & 3.30 & 1.44 & 1.86 & 0.74 & 0.95 & 0.57 & 0.26 & 0.05 & 0.02 \\
\hline 24 & 2.61 & 1.38 & 1.24 & 0.69 & 0.86 & 0.61 & 0.26 & 0.07 & 0.02 \\
\hline 25 & 2.28 & 1.48 & 0.80 & 0.60 & 0.87 & 0.54 & 0.20 & 0.08 & 0.03 \\
\hline 26 & 1.76 & 1.43 & 0.33 & 0.54 & 0.74 & 0.48 & 0.21 & 0.10 & 0.02 \\
\hline 27 & 1.39 & 1.23 & 0.16 & 0.50 & 0.69 & 0.47 & 0.56 & 0.21 & 0.02 \\
\hline 28 & 1.03 & 0.67 & 0.36 & 0.36 & 0.62 & 0.40 & 0.37 & 0.11 & 0.02 \\
\hline 29 & 0.76 & 0.65 & 0.11 & 0.32 & 0.51 & 0.48 & 0.67 & 0.23 & 0.02 \\
\hline 30 & 0.52 & 0.25 & 0.26 & 0.25 & 0.37 & 0.36 & 0.47 & 0.25 & 0.01 \\
\hline 31 & 0.31 & 0.20 & 0.12 & 0.17 & 0.31 & 0.25 & 0.21 & 0.11 & 0.01 \\
\hline 32 & 0.18 & 0.11 & 0.07 & 0.11 & 0.27 & 0.14 & 0.12 & 0.07 & 0.01 \\
\hline 33 & 0.14 & 0.09 & 0.05 & 0.09 & 0.17 & 0.13 & 0.09 & 0.04 & 0.01 \\
\hline 34 & 0.07 & & 0.07 & 0.06 & 0.16 & 0.09 & 0.05 & 0.03 & 0.00 \\
\hline 35 & 0.06 & & 0.06 & 0.05 & 0.11 & 0.05 & 0.03 & 0.02 & 0.00 \\
\hline 36 & 0.03 & & 0.03 & 0.03 & 0.07 & 0.03 & 0.03 & 0.01 & 0.00 \\
\hline 37 & 0.05 & & 0.05 & 0.03 & 0.05 & 0.06 & 0.03 & 0.01 & 0.00 \\
\hline 38 & 0.02 & & 0.02 & 0.01 & 0.07 & 0.03 & 0.02 & 0.01 & 0.00 \\
\hline 39 & 0.01 & & 0.01 & 0.01 & 0.02 & 0.01 & 0.01 & & 0.00 \\
\hline 40 & & & & 0.01 & 0.01 & & & & \\
\hline 41 & & & & & 0.02 & & & & \\
\hline \multicolumn{10}{|l|}{42} \\
\hline Total & 36.60 & 15.22 & 21.38 & 9.60 & 12.10 & 8.10 & 4.70 & 1.70 & 0.30 \\
\hline
\end{tabular}


Table S3. Carbon number distribution of aroma in waxy oil

\begin{tabular}{|c|c|c|c|c|c|c|c|c|c|c|c|c|c|c|}
\hline Z & -6 & -8 & -10 & -12 & -14 & -16 & -18 & $\begin{array}{l}-20 / \\
-10 \mathrm{~S}\end{array}$ & -22 & -24 & $-16 \mathrm{~S}$ & -28 & -30 & $-22 \mathrm{~S}$ \\
\hline $\mathrm{C} \#$ & $\begin{array}{c}\text { Alkyl } \\
\text { benzene }\end{array}$ & $\begin{array}{l}\text { Naphthenic } \\
\text { benzene }\end{array}$ & $\begin{array}{c}\text { Bicyclic } \\
\text { alkylbenzene }\end{array}$ & $\begin{array}{c}\text { Naphtha } \\
\text { lenes }\end{array}$ & $\begin{array}{c}\text { Acenaphthe } \\
\text { ne }+ \\
\text { Dibenzofura } \\
\text { n }\end{array}$ & $\begin{array}{c}\text { Fluore } \\
\text { ne }\end{array}$ & $\begin{array}{c}\text { Phena } \\
\text { nthren } \\
\text { es }\end{array}$ & $\begin{array}{c}\text { Naphthenic } \\
\text { phenanthrene } \\
\text { / } \\
\text { Benzothiophe } \\
\text { ne }\end{array}$ & $\begin{array}{c}\text { Pyren } \\
\text { es }\end{array}$ & $\begin{array}{c}\text { Flexio } \\
\mathrm{n}\end{array}$ & $\begin{array}{l}\text { Diben } \\
\text { zothio } \\
\text { phene }\end{array}$ & $\begin{array}{c}\text { Peryle } \\
\text { nes }\end{array}$ & $\begin{array}{l}\text { Diben } \\
\text { zanthr } \\
\text { acene }\end{array}$ & $\begin{array}{l}\text { Naphthoben } \\
\text { zothiophene }\end{array}$ \\
\hline \multicolumn{15}{|l|}{11} \\
\hline \multicolumn{15}{|l|}{12} \\
\hline 13 & & 0.03 & 0.02 & 0.23 & 0.01 & & & & & & 0.02 & & & \\
\hline 14 & 0.04 & 0.08 & 0.03 & 0.21 & 0.06 & 0.06 & & & & & 0.04 & & & \\
\hline 15 & 0.06 & 0.07 & 0.08 & 0.19 & 0.19 & 0.11 & 0.16 & 0.02 & & & 0.04 & & & \\
\hline 16 & 0.07 & 0.12 & 0.10 & 0.13 & 0.30 & 0.26 & 0.30 & 0.03 & 0.02 & & 0.02 & & & \\
\hline 17 & 0.13 & 0.16 & 0.23 & 0.11 & 0.34 & 0.25 & 0.30 & 0.11 & 0.08 & & 0.02 & & & 0.03 \\
\hline 18 & 0.22 & 0.16 & 0.28 & 0.16 & 0.30 & 0.29 & 0.21 & 0.22 & 0.15 & 0.06 & 0.02 & & & 0.04 \\
\hline 19 & 0.33 & 0.27 & 0.35 & 0.19 & 0.19 & 0.30 & 0.17 & 0.22 & 0.19 & 0.12 & 0.02 & 0.17 & & 0.04 \\
\hline 20 & 0.45 & 0.41 & 0.30 & 0.21 & 0.17 & 0.29 & 0.13 & 0.22 & 0.14 & 0.11 & 0.01 & 0.08 & & \\
\hline 21 & 0.41 & 0.41 & 0.37 & 0.19 & 0.16 & 0.25 & 0.14 & 0.19 & 0.10 & 0.08 & 0.01 & 0.05 & & \\
\hline 22 & 0.42 & 0.39 & 0.29 & 0.15 & 0.10 & 0.20 & 0.11 & 0.12 & 0.08 & 0.05 & 0.00 & & & \\
\hline 23 & 0.34 & 0.28 & 0.29 & 0.15 & 0.10 & 0.14 & 0.08 & 0.07 & 0.06 & 0.04 & 0.01 & & & \\
\hline 24 & 0.26 & 0.24 & 0.23 & 0.12 & 0.09 & 0.12 & 0.07 & 0.07 & 0.05 & 0.04 & & & & \\
\hline 25 & 0.30 & 0.30 & 0.26 & 0.10 & 0.06 & 0.08 & 0.07 & 0.04 & 0.02 & 0.02 & & & & \\
\hline 26 & 0.24 & 0.23 & 0.16 & 0.10 & 0.06 & 0.07 & 0.06 & 0.05 & 0.04 & 0.03 & & & & \\
\hline
\end{tabular}


Supporting Information

\begin{tabular}{|c|c|c|c|c|c|c|c|c|c|c|c|c|c|}
\hline 27 & 0.33 & 0.27 & 0.20 & 0.08 & 0.06 & 0.07 & 0.05 & 0.04 & 0.02 & 0.02 & & & \\
\hline 28 & 0.20 & 0.15 & 0.14 & 0.06 & 0.04 & 0.06 & 0.07 & 0.05 & 0.03 & 0.02 & & & \\
\hline 29 & 0.24 & 0.13 & 0.13 & 0.08 & 0.05 & 0.05 & 0.05 & 0.03 & 0.01 & 0.01 & & & \\
\hline 30 & 0.12 & 0.11 & 0.10 & 0.05 & 0.04 & 0.03 & 0.06 & 0.02 & 0.02 & 0.01 & & & \\
\hline 31 & 0.11 & 0.11 & 0.08 & 0.03 & 0.02 & 0.02 & 0.01 & & & & & & \\
\hline 32 & 0.08 & 0.05 & 0.06 & 0.02 & 0.03 & 0.03 & 0.03 & & & & & & \\
\hline 33 & 0.06 & 0.05 & 0.04 & 0.02 & 0.01 & 0.01 & 0.01 & & & & & & \\
\hline 34 & 0.04 & 0.03 & 0.02 & 0.01 & 0.01 & 0.01 & 0.01 & & & & & & \\
\hline 35 & 0.03 & 0.04 & 0.03 & 0.01 & 0.01 & 0.01 & 0.01 & & & & & & \\
\hline 36 & & 0.02 & 0.02 & & & & & & & & & & \\
\hline \multicolumn{14}{|l|}{37} \\
\hline \multicolumn{14}{|l|}{38} \\
\hline \multicolumn{14}{|l|}{39} \\
\hline \multicolumn{14}{|l|}{40} \\
\hline \multicolumn{14}{|l|}{41} \\
\hline Total & 4.50 & 4.10 & 3.80 & 2.60 & 2.40 & 2.70 & 2.10 & 1.50 & 1.00 & 0.60 & 0.20 & 0.30 & 0.10 \\
\hline
\end{tabular}


Table S4. Carbon number distribution of saturated hydrocarbon in the residual oil

\begin{tabular}{|c|c|c|c|c|c|c|c|}
\hline $\mathrm{Z}$ & +2 & 0 & -2 & -4 & -6 & -8 & -10 \\
\hline $\mathrm{C} \#$ & Alkane & Cycloalkane & $\begin{array}{c}\text { Bicyclic } \\
\text { alkane }\end{array}$ & $\begin{array}{c}\text { Tricyclic } \\
\text { alkane }\end{array}$ & $\begin{array}{c}\text { Tetracyclic } \\
\text { alkane }\end{array}$ & Pentacycloalkanes & Hexacycloalkane \\
\hline 11 & 0.00 & 0.05 & 0.00 & 0.00 & 0.00 & 0.00 & 0.00 \\
\hline 12 & 0.03 & 0.09 & 0.00 & 0.00 & 0.00 & 0.00 & 0.00 \\
\hline 13 & 0.06 & 0.10 & 0.00 & 0.00 & 0.00 & 0.00 & 0.00 \\
\hline 14 & 0.28 & 0.14 & 0.00 & 0.00 & 0.00 & 0.00 & 0.00 \\
\hline 15 & 0.23 & 0.24 & 0.09 & 0.00 & 0.00 & 0.00 & 0.00 \\
\hline 16 & 0.56 & 0.37 & 0.18 & 0.22 & 0.00 & 0.00 & 0.00 \\
\hline 17 & 0.62 & 0.36 & 0.27 & 0.16 & 0.03 & 0.00 & 0.00 \\
\hline 18 & 1.18 & 0.56 & 0.30 & 0.37 & 0.07 & 0.01 & 0.00 \\
\hline 19 & 1.58 & 0.58 & 0.39 & 0.68 & 0.12 & 0.02 & 0.00 \\
\hline 20 & 3.15 & 1.14 & 0.59 & 0.78 & 0.13 & 0.05 & 0.00 \\
\hline 21 & 4.68 & 1.44 & 1.04 & 1.65 & 0.40 & 0.12 & 0.00 \\
\hline 22 & 5.31 & 1.79 & 1.52 & 1.12 & 0.26 & 0.06 & 0.00 \\
\hline 23 & 5.08 & 1.84 & 1.66 & 1.65 & 0.34 & 0.05 & 0.00 \\
\hline 24 & 2.96 & 1.55 & 1.57 & 1.37 & 0.49 & 0.16 & 0.00 \\
\hline 25 & 1.92 & 1.12 & 1.79 & 1.24 & 0.20 & 0.06 & 0.00 \\
\hline 26 & 1.21 & 0.92 & 1.29 & 0.93 & 0.21 & 0.09 & 0.00 \\
\hline 27 & 1.02 & 0.70 & 1.20 & 0.81 & 0.46 & 0.17 & 0.00 \\
\hline 28 & 1.03 & 0.55 & 1.00 & 0.81 & 0.40 & 0.09 & 0.00 \\
\hline 29 & 0.80 & 0.70 & 0.70 & 0.96 & 0.74 & 0.25 & 0.00 \\
\hline 30 & 0.74 & 0.65 & 0.66 & 0.99 & 0.57 & 0.35 & 0.00 \\
\hline 31 & 0.57 & 0.52 & 0.64 & 0.53 & 0.34 & 0.18 & 0.00 \\
\hline 32 & 0.47 & 0.48 & 0.59 & 0.43 & 0.20 & 0.12 & 0.00 \\
\hline 33 & 0.39 & 0.40 & 0.57 & 0.47 & 0.18 & 0.09 & 0.00 \\
\hline 34 & 0.27 & 0.33 & 0.61 & 0.53 & 0.15 & 0.07 & 0.00 \\
\hline 35 & 0.27 & 0.37 & 0.50 & 0.34 & 0.12 & 0.05 & 0.00 \\
\hline 36 & 0.23 & 0.29 & 0.48 & 0.25 & 0.08 & 0.04 & 0.00 \\
\hline 37 & 0.21 & 0.29 & 0.36 & 0.25 & 0.07 & 0.03 & 0.00 \\
\hline 38 & 0.21 & 0.21 & 0.34 & 0.22 & 0.08 & 0.03 & 0.00 \\
\hline 39 & 0.14 & 0.22 & 0.32 & 0.28 & 0.05 & 0.03 & 0.00 \\
\hline 40 & 0.14 & 0.16 & 0.30 & 0.31 & 0.06 & 0.00 & 0.00 \\
\hline 41 & 0.12 & 0.12 & 0.52 & 0.16 & 0.03 & 0.00 & 0.00 \\
\hline 42 & 0.12 & 0.10 & 0.20 & 0.12 & 0.00 & 0.00 & 0.00 \\
\hline 43 & 0.07 & 0.07 & 0.16 & 0.16 & 0.00 & 0.00 & 0.00 \\
\hline 44 & 0.05 & 0.08 & 0.11 & 0.00 & 0.00 & 0.00 & 0.00 \\
\hline 45 & 0.00 & 0.00 & 0.11 & 0.00 & 0.00 & 0.00 & 0.00 \\
\hline 46 & 0.00 & 0.00 & 0.00 & 0.00 & 0.00 & 0.00 & 0.00 \\
\hline Total & 35.71 & 18.53 & 20.08 & 17.76 & 5.79 & 2.12 & 0.00 \\
\hline
\end{tabular}


Table S5. Compound type composition of the residual oil

\begin{tabular}{lr}
\hline Compound type & $\begin{array}{r}\text { Relative abundance } \\
\text { (wt.\%) }\end{array}$ \\
\hline HC & 57.09 \\
S1 & 4.53 \\
S2 & 0.03 \\
S3 & 0.03 \\
N1 & 21.14 \\
N2 & 1.04 \\
O1 & 11.53 \\
O2 & 1.15 \\
N1S1 & 0.36 \\
N1O1 & 2.91 \\
N1O2 & 0.09 \\
S1O1 & \\
S1O2 & 0.06 \\
N1S1O1 & 0.02 \\
Total & 0.02 \\
&
\end{tabular}




\section{Key molecular structures of the FCC feed oil}

46 key molecular structures were obtained according to the characterization results of feedstock ${ }^{1}$.

\begin{tabular}{|c|c|c|c|c|}
\hline 0 & $\infty$ & 000000080 & 0 & 02000000000 \\
\hline$\infty \infty$ & $\infty$ & $\infty \infty$ & $\infty$ & 003000000080 \\
\hline$\infty 00$ & $0-\infty$ & $\infty \quad \infty 00$ & $\infty$ & 0802008 \\
\hline & & $\infty 20$ & & 0200 \\
\hline 800200 & $\infty$ & 0237023 & D & \\
\hline$\infty$ & $\infty$ & 0000 & $\infty$ & \\
\hline 80 & 00 & 20 & & \\
\hline
\end{tabular}

Figure S1. Key molecular structure 


\section{Data pre-processing}

1 ) Outlier identification and processing. Descriptive statistical analysis on the collected production data was carried out, and the distribution characteristics, types and statistical significance of the data were analyzed to determine whether there were missing values and outliers in the dataset. Percentile method was the default method for judging the outliers in the datasets; interpolation fitting method was then used to fill in missing and outliers.

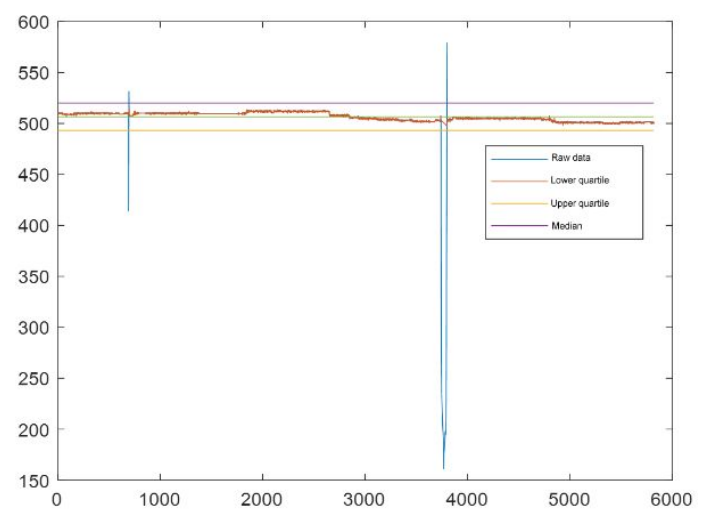

(a)

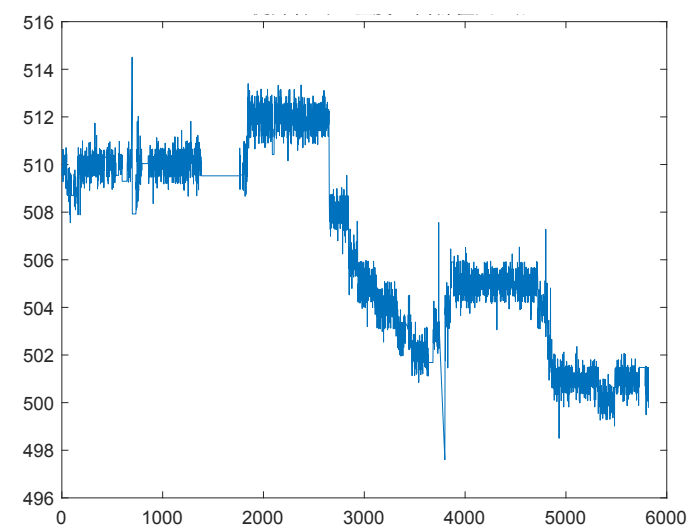

(b)

Figure S2. Taking the outlet temperature TIC3101 of the riser as an example.

(a) The outliers processing of the data set was carried out by quartile method; (b) automatic filling was performed by linear interpolation after outlier processing

2) Data smoothing and noise reduction. The quadratic regression function was employed to denoise, filter the high frequency noise signal to get a data set conformed to the data evolution trend. Taking TIC3101 as an example, comparing the data before and after noise reduction, it can be seen that the smoothed dataset retains the low frequency band which represents the signal trend, as shown in Figure 3. 
Supporting Information

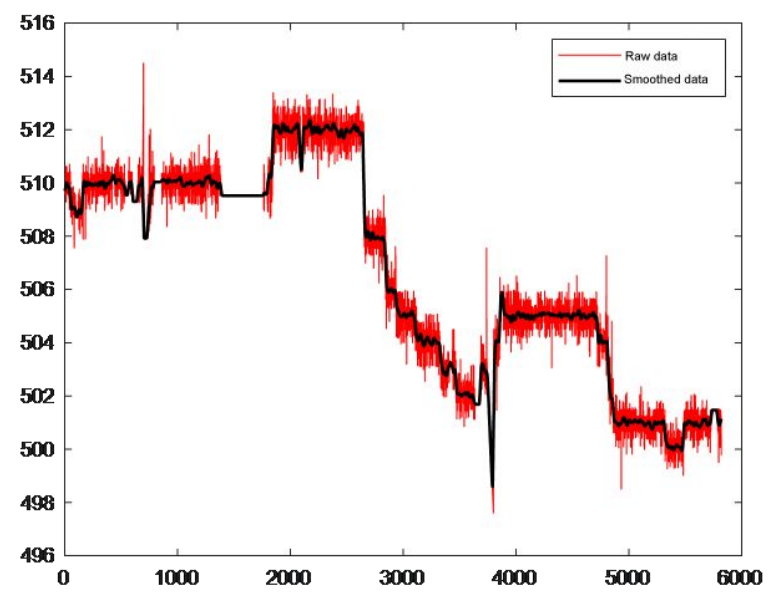

Figure S3. Comparison of the outlet temperature TIC 3101 of the riser before and after data smoothing.

10 


\section{The steady-state analysis}

Steady state of process is a common assumption in chemical process simulation. Both the material balance and process design are carried out on such assumption. In addition, whether the system is in a steady state may directly relate to the subsequent methods of control and optimization of the system, so it is crucial to carry out the steady-state analysis of complex processes and analyze the corresponding operating conditions under each steady state.

Since the steady-state analysis was proposed in the 1980s, many methods have been developed, such as CST method based on statistical detection, confidence method, polynomial filtering method based on trend extraction, wavelet decomposition method, etc. Wavelet decomposition method has a good capability of time-frequency localization and multi-resolution analysis, and is a powerful tool for non-stationary signal analysis. Therefore, this paper used wavelet decomposition method based on trend extraction for the steady-state analysis.

1) Trend extraction. Wavelet transform decomposed the signal into the high frequency band noise and the low frequency band representing the signal trend. An approximate function of process variables was obtained in the low frequency band and noted as $\mathrm{f}(\mathrm{t})$. Fig. S4 shows the dense phase temperature TIC3102 of the second regenerator. The original signal information S is represented by the red line, the trend information of signal $\mathrm{f}(\mathrm{t})$ is represented by the black line, and the blue line represents the high frequency noise of signal $\mathrm{D}$, then the original signal $\mathrm{S}$ can be expressed as: $\mathrm{S}=$ $f(t)+D$.
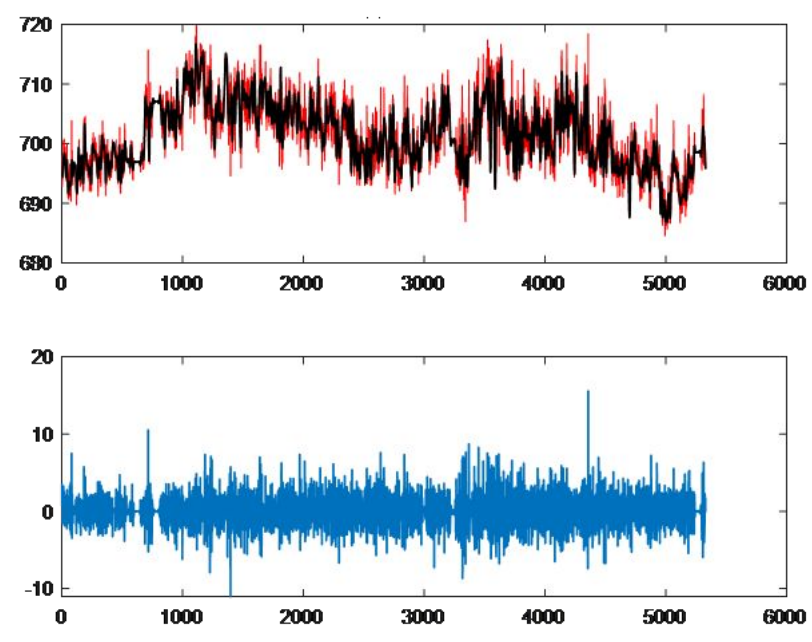
Figure S4. Trend extraction of the dense phase temperature TIC3102 of the second regenerator.

2) Steady State Criteria. The steady-state index $\beta(0 \leq \beta \leq 1)$ was established to represent the degree of stability of process variables. $\beta=0$ indicates that the process variables were under an unsteady state; $\beta=1$ indicates that the process variables were under a steady state; $0<\beta<1$ then indicates that the process variables were under a transient state, and the closer $\beta$ was to 1 , the more stable the state of the process variable was.

The steady-state index $\beta(\mathrm{t})$ was derived from the first derivative $f^{\prime}\left(t_{0}\right)$ and the second derivative $f^{\prime \prime}\left(t_{0}\right)$ of the data trend based on the following criteria:

$$
\theta(t)=\left|f^{\prime}(t)\right|+\gamma\left|f^{\prime \prime}(t)\right|
$$

where :

$$
\begin{gathered}
\gamma=\left\{\begin{array}{cc}
0, & \left|f^{\prime \prime}(t)\right| \leq T_{w} \\
\frac{\left(\left|f^{\prime \prime}(t)\right|-T_{w}\right)}{2 T_{w}}, & T_{w} \leq\left|f^{\prime \prime}(t)\right|<3 T_{w} \\
1, & \left|f^{\prime \prime}(t)\right| \geq 3 T_{w}
\end{array}\right. \\
\beta(\mathrm{t})=\left\{\begin{array}{cc}
0, & \theta(t)>T_{u} \\
1 / 2\left[\cos \left(\frac{\theta(t)-T_{s}}{T_{u}-T_{s}} \pi\right)+1\right], & T_{s} \leq \theta(t)<T_{u} \\
1, & \theta(t) \leq T_{s}
\end{array}\right.
\end{gathered}
$$

3) Threshold determination. A segment of steady-state data was firstly selected as a reference, the evolution trend of the process variables was then acquired through the wavelet transformation, the first and second derivative sequences of process variables at the sampling points were obtained, and then the percentiles (generally $90 \%$ or $95 \%$ quantile) of the process variables were calculated respectively.

$$
T_{u}=\alpha T_{s}
$$

$T_{s}$ is the percentile of the first derivative, $T_{w}$ is the percentile of the second derivative, $\alpha$ is the adjustable parameter, often taken an integer in the range of $[2,5]$. The threshold of the steady state criteria of process variables was then obtained according to the above formula.

Taking TIC3102 as an example, the steady-state analysis of this variable was carried out through the below steps. (1) Reference selection. Based on the evolution trend of the variables in Figure S5a, a relatively smooth section of data with sampling numbers from 1518 to 2138 was selected as the reference, $T_{S}$ was the $90 \%$ quantile of the first derivative, $T_{w}$ was the $95 \%$ quantile of second derivative, and $\alpha=3$. (2) Steady state judgment. Steady state judgment of all process 
variables data was carried out, as shown in Fig. S5b, the steady-state index was able to fully represent the status of process variables and accurately detect unsteady, transient and steady state of process.
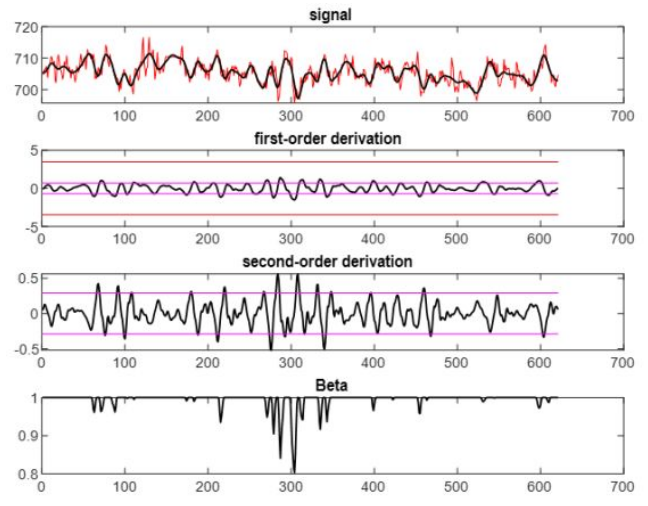

(a)

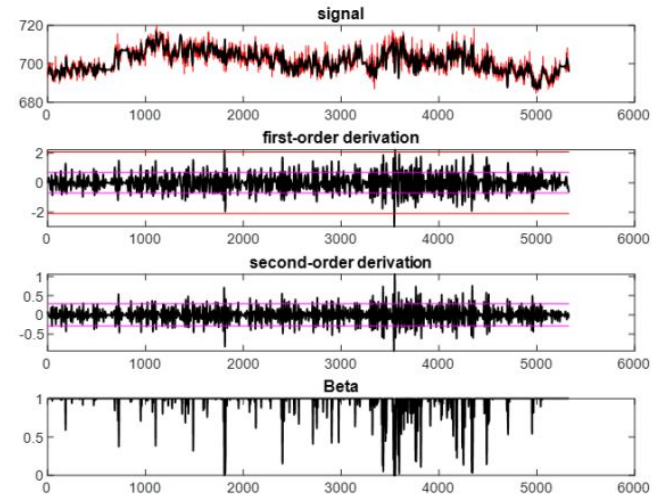

(b)

Figure S5. (a)TIC3102 basis reference; (b) TIC3102 steady-state analysis results

4) Multivariable steady state detection

Whether the process of a system is stable or not depends on the stability of all its variables. 42 production process variables were considered in this work. The steady-state conditions of the entire system were determined by their steady-state index, weighted as follows:

$$
B(t)=\prod_{i=1}^{p}\left[\beta_{i}(t)\right]^{u_{i} / \sum_{i=1}^{p} u_{i}}
$$

Where, $\mathrm{p}$ is the number of the key characteristic variables of the system, $\beta_{i}(t)$ is the steadystate index of the $\mathrm{i}^{\text {th }}$ variable, $u_{i}$ is the weight of the $\mathrm{i}^{\text {th }}$ variable, here $u_{i}=1$, the result is shown in Fig. S6.

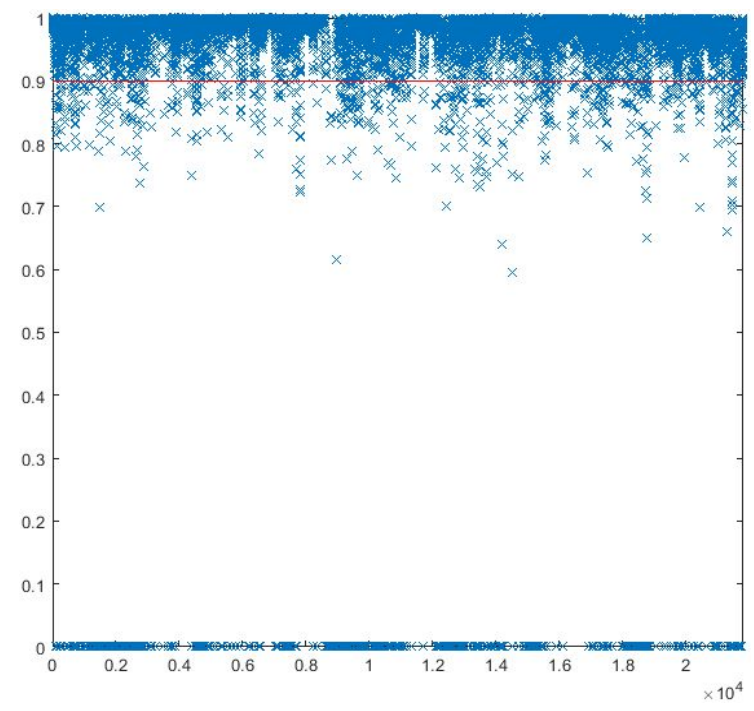


Figure S6. Multivariable steady-state index

Data points with steady-state index greater than 0.9 were taken as the indicators for steadystate judgment. In addition, the actual steady state was considered to be reached only when the steady state lasted for certain period of time. Since the sample interval used for steady state judgment was $1 \mathrm{~h}$, the time threshold for steady state judgment of the system was then set for $4 \mathrm{~h}$. Therefore, the system was considered to be stable when its steady-state index was greater than 0.9 for 4 consecutive hours. The steady-state index $\beta=1$ was taken under a steady state, and $\beta=0$ under an unsteady state, then the dataset of system status after steady state judgement was obtained and shown in Fig.S7.

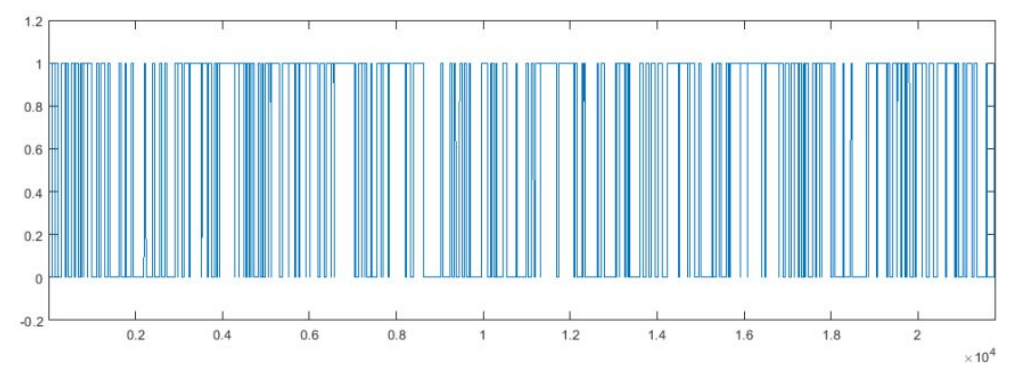

Figure S7. Steady-state judgement of the system 


\section{The input variables for modeling}

Table S6. DCS tag number selected for modeling

\begin{tabular}{|c|c|c|c|c|c|}
\hline$\#$ & DCS tag number & Location/remark & \# & $\begin{array}{l}\text { DCS tag } \\
\text { number }\end{array}$ & Location/remark \\
\hline 1 & TI3106B & Top of quench nozzle & 22 & PI3110 & $\begin{array}{l}\text { Pressure in the second } \\
\text { stage of the two- } \\
\text { stages regenerator }\end{array}$ \\
\hline 2 & TI3106A & Bottom of quench nozzle & 23 & DI3112 & $\begin{array}{l}\text { Density in the second stage of } \\
\text { the two-stages regenerator }\end{array}$ \\
\hline 3 & TI3111 & Part of ' $Y$ ' form & 24 & FIC3122 & Main air flow rate \\
\hline 4 & TI3228 & $\begin{array}{l}\text { Return refinery extraction } \\
\text { temperature }\end{array}$ & 25 & FIC3119 & Combustion oil flow rate \\
\hline 5 & FIC3105 & $\begin{array}{l}\text { Atomizing steam flow rate of return } \\
\text { refining slurry }\end{array}$ & 26 & TI3131A & $\begin{array}{l}\text { The bottom of second stage in } \\
\text { the two-stages regenerator }\end{array}$ \\
\hline 6 & FIC3208 & Residuum oil flow rate & 27 & TI3220C & Bottom of herringbone baffle \\
\hline 7 & FIC3209 & Wax oil flow rate & 28 & TI3222 & Oil gas entrance \\
\hline 8 & FIC3109 & Bottom flow of fluidized steam & 29 & PI3203 & Tower top pressure \\
\hline 9 & PdI3122 & Riser pressure drop & 30 & TIC3201 & Tower top temperature \\
\hline 10 & PdIC3103 & $\begin{array}{l}\text { Pressure drop of regenerative slide } \\
\text { valve }\end{array}$ & 31 & TI3209B & $\begin{array}{l}\text { Temperature in the } 16 \text { th floor } \\
\text { tray gas phase }\end{array}$ \\
\hline 11 & DI3102 & Density in the riser & 32 & TIC3203 & Top of herringbone baffle \\
\hline 12 & TIC3101 & Riser outlet temperature & 33 & FIC3206 & Top return tower flow rate \\
\hline 13 & TIC3204 & Preheating temperature of feed oil & 34 & FIC 3213 & Lean absorption oil \\
\hline 14 & FIC3111 & Pre-lift steam flow & 35 & FIC3201 & First medium return tower \\
\hline 15 & FIC3110 & Pre-lift dry gas flow & 36 & FIC3207 & Second medium return tower \\
\hline 16 & PI3106 & Pressure in the top of settler & 37 & FIC3202 & Return refinery return tower \\
\hline 17 & FIC3112_3117 & Steam flow rate of settler & 38 & FIC3203_3204 & Slurry flow back to the tower \\
\hline 18 & TI3117 & $\begin{array}{l}\text { Front temperature of spent } \\
\text { regeneration valve }\end{array}$ & 39 & FIC3214 & Steam-agitated flow rate \\
\hline 19 & TIC3125 & $\begin{array}{l}\text { The first stage of the two- } \\
\text { stages regenerator }\end{array}$ & 40 & LIC3201 & Liquid level \\
\hline 20 & TI3126A & $\begin{array}{l}\text { The bottom of first stage in the two- } \\
\text { stages regenerator }\end{array}$ & 41 & LIC3207 & $\begin{array}{l}\text { Liquid level at the top of } \\
\text { fractionating tower }\end{array}$ \\
\hline 21 & TIC3102 & $\begin{array}{l}\text { Temperature in the second stage of } \\
\text { the two-stages regenerator }\end{array}$ & 42 & LIC3208 & $\begin{array}{l}\text { Boundary at the top of } \\
\text { fractionating tower }\end{array}$ \\
\hline
\end{tabular}


Table S7. LIMS properties selected for modeling

\begin{tabular}{lcc}
\hline$\#$ & Analysis item & Unit \\
\hline 1 & $10 \%$ Distillation point & ${ }^{\circ} \mathrm{C}$ \\
2 & $30 \%$ Distillation point & ${ }^{\circ} \mathrm{C}$ \\
3 & $5 \%$ Distillation point & ${ }^{\circ} \mathrm{C}$ \\
4 & $50 \%$ Distillation point & ${ }^{\circ} \mathrm{C}$ \\
5 & $70 \%$ Distillation point & ${ }^{\circ} \mathrm{C}$ \\
6 & Carbon residue content & $\mathrm{wt} \%$ \\
7 & Initial boiling point & ${ }^{\circ} \mathrm{C}$ \\
8 & Density & $\mathrm{kg} / \mathrm{m}^{3}$ \\
9 & Sulphur content & $\mathrm{wt} \%$ \\
\hline
\end{tabular}




\section{Feature importance}

Catboost is able to measure the importance of input features according to Eq. 1 listed below: the larger the value of importance, the greater the impact on the prediction results. Since the formula are non-linear, it can explain the model and compare different characteristics.

$$
F I=\sum\left(v_{1}-\frac{v_{1} \cdot c_{1}+v_{2} \cdot c_{2}}{c_{1}+c_{2}}\right)^{2} \cdot c_{1}+\left(v_{2}-\frac{v_{1} \cdot c_{1}+v_{2} \cdot c_{2}}{c_{1}+c_{2}}\right)^{2} \cdot c_{2}
$$

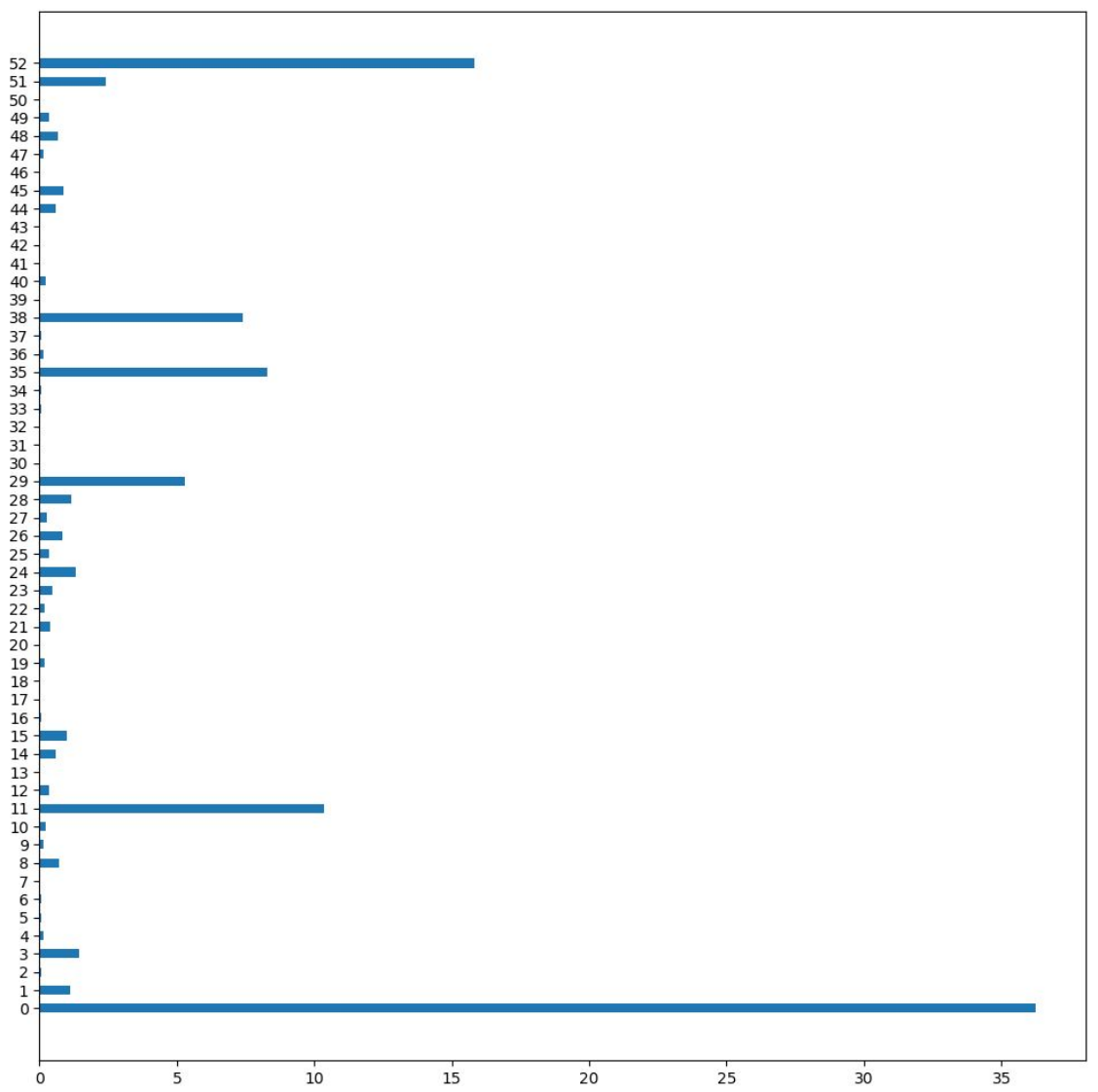

Figure S8. Visualization of the feature importance on the dry gas yield 


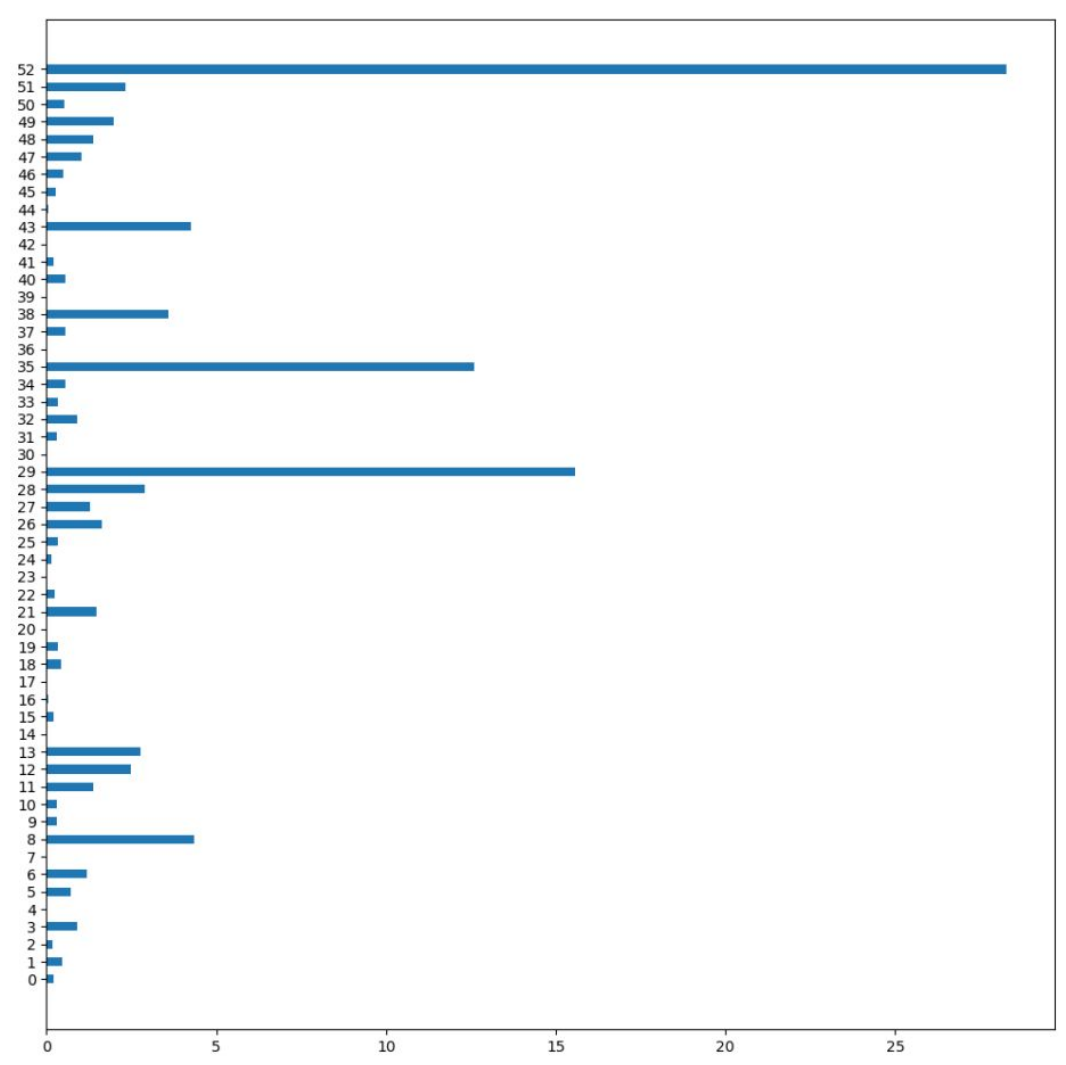

Figure S9. Visualization of the feature importance on the LPG yield

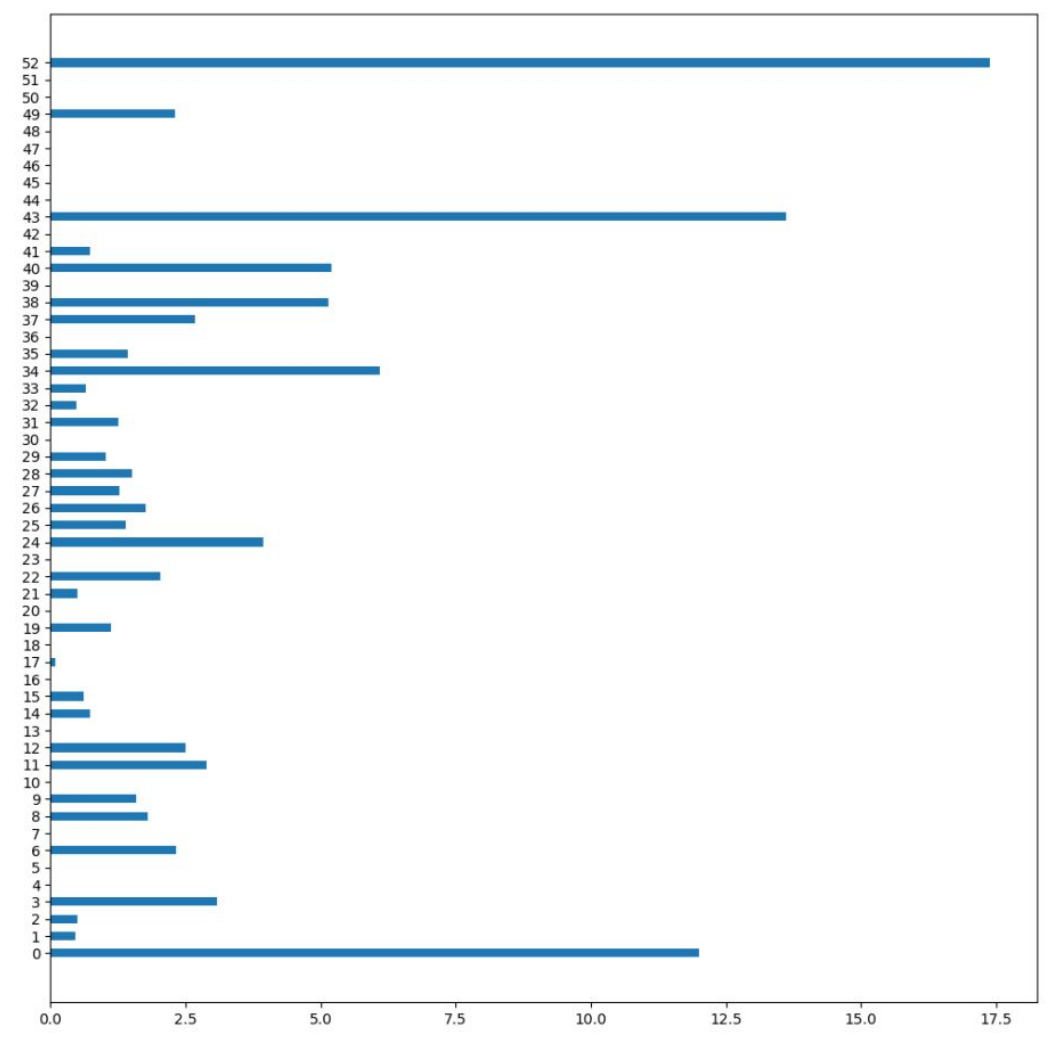

Figure S10. Visualization of the feature importance on the gasoline yield 


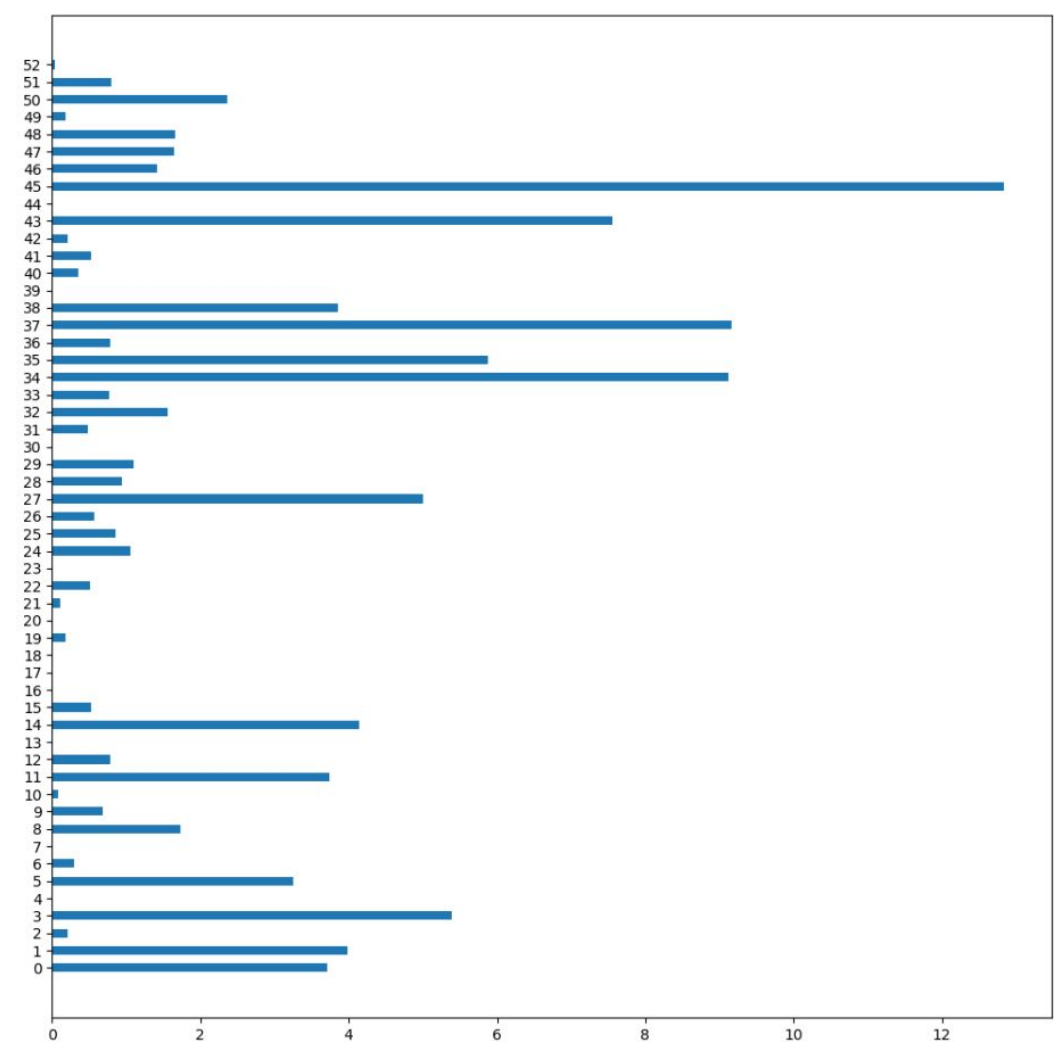

Figure S11. Visualization of the feature importance on the diesel yield

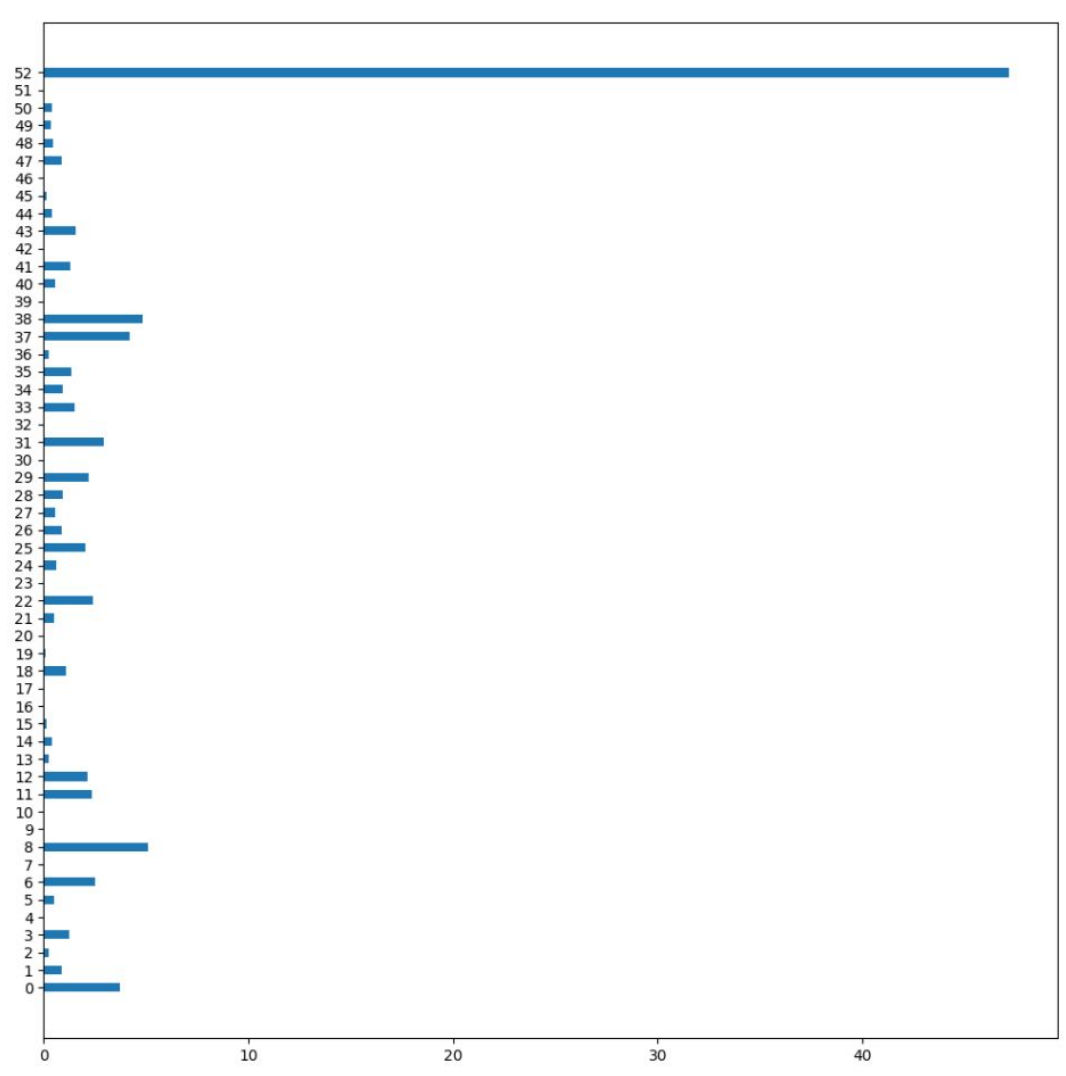

Figure S12. Visualization of the feature importance on the $90 \%$ gasoline 


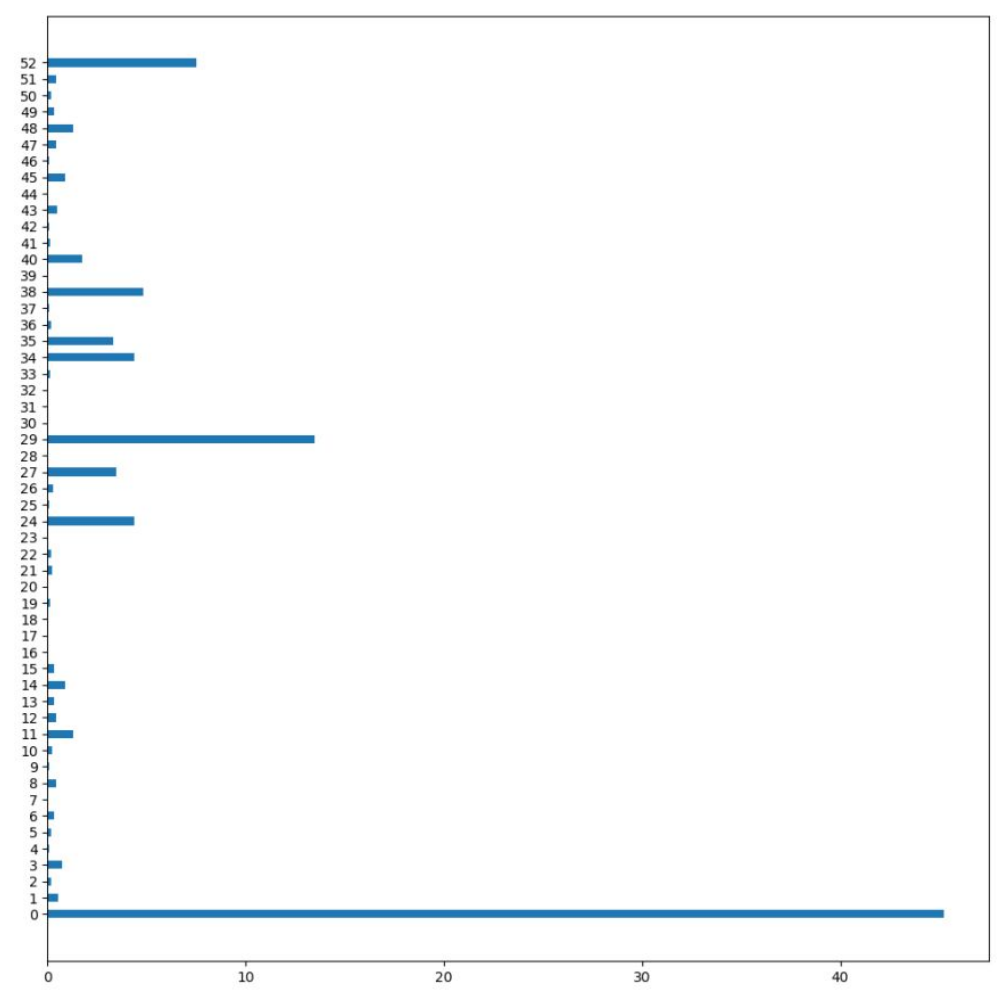

Figure S13. Visualization of the feature importance on the gasoline olefins

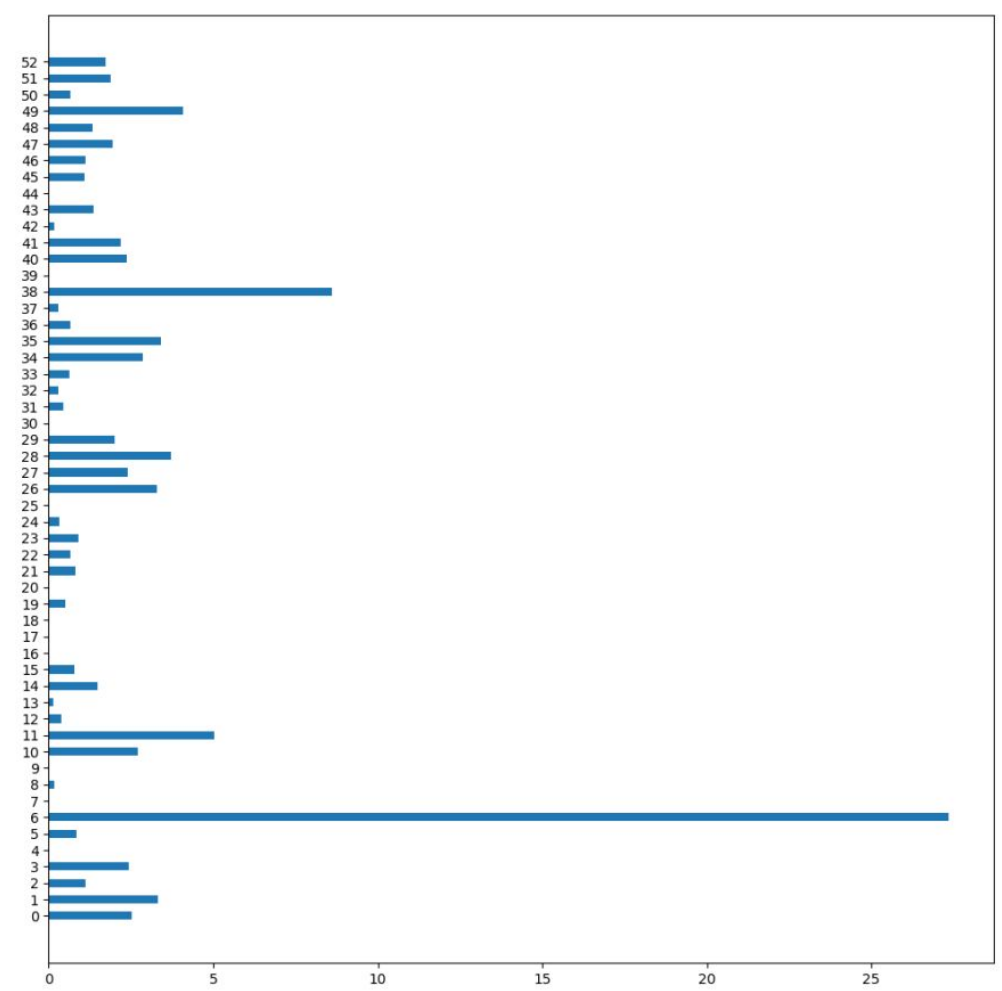

Figure S14. Visualization of the feature importance on the $50 \%$ diesel 


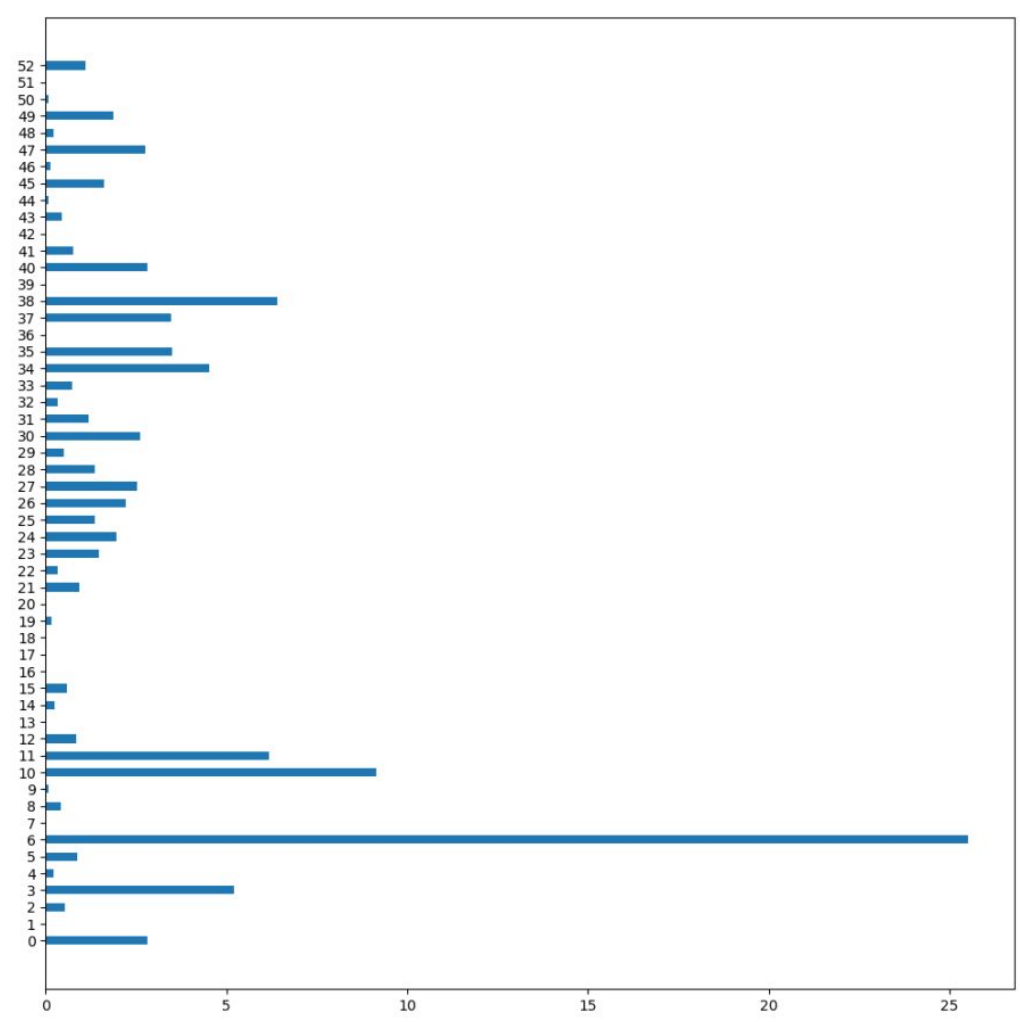

Figure S15. Visualization of the feature importance on the $90 \%$ diesel

\section{References}

1. Kim, E.-K.; No, M.-H.; Koh, J.-S.; Kim, S., Compositional Characterization of Petroleum Heavy Oils Generated from Vacuum Distillation and Catalytic Cracking by Positive-mode APPI FT-ICR Mass Spectrometry. Mass Spectrometry Letters 2011, 2, 41-44. 